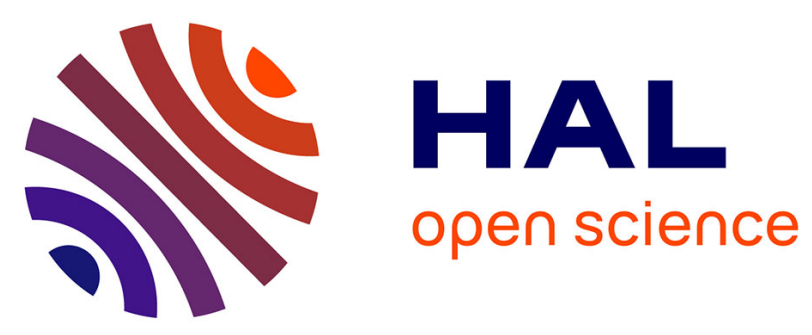

\title{
Antibiotic susceptibilities of livestock isolates of leptospira
}

Geoffroy Liegeon, Tristan Delory, Mathieu Picardeau

\section{To cite this version:}

Geoffroy Liegeon, Tristan Delory, Mathieu Picardeau. Antibiotic susceptibilities of livestock isolates of leptospira. International Journal of Antimicrobial Agents, 2018, 51 (5), pp.693-699. 10.1016/j.ijantimicag.2017.12.024 . pasteur-02548686

\section{HAL Id: pasteur-02548686}

\section{https://hal-pasteur.archives-ouvertes.fr/pasteur-02548686}

Submitted on 20 Apr 2020

HAL is a multi-disciplinary open access archive for the deposit and dissemination of scientific research documents, whether they are published or not. The documents may come from teaching and research institutions in France or abroad, or from public or private research centers.
L'archive ouverte pluridisciplinaire HAL, est destinée au dépôt et à la diffusion de documents scientifiques de niveau recherche, publiés ou non, émanant des établissements d'enseignement et de recherche français ou étrangers, des laboratoires publics ou privés.

\section{(이) $\$$}

Distributed under a Creative Commons Attribution - NonCommercial - NoDerivatives $\mid 4.0$ 


\section{Antibiotic susceptibilities of livestock isolates of Leptospira}

2

3 Geoffroy LIEGEON ${ }^{1}$, Tristan DELORY², and Mathieu PICARDEAU ${ }^{1 *}$

4

5

6

71 Institut Pasteur, Biology of Spirochetes unit, French National Reference Center for

8 Leptospirosis, Paris, France

$9{ }^{2}$ Assistance publique-Hôpitaux de Paris, Hopital Saint-Louis, Paris, Department of Infectious

10 Diseases, Paris, France

11

12

13

14

15

16 Corresponding Author

$17 \quad$ mathieu.picardeau@pasteur.fr

18 *Present address

19 Unité Biologie des spirochètes,

20 Institut Pasteur, 28 rue du Docteur Roux,

2175724 PARIS Cedex 15,

22 France,

23 Phone : + $33(1) 45688368$,

24 Fax : + $33(1) 40613001$

25

26 Running head: Antibiotic Susceptibilities of Leptospira strains 


\section{Abstract}

Leptospirosis is the most common zoonotic disease and is endemic worldwide. The antibiotic susceptibilities of Leptospira isolated from both humans and animals are poorly documented. This issue is particularly important for isolates from food-producing animals which are regularly exposed to antibiotic treatments. In this study, we assess the susceptibility of 35 Leptospira strains isolated from food-producing animals of diverse geographical origins between 1936 and 2016 to the antimicrobial agents most commonly used in animals. We used a broth microdilution method to determine the susceptibilities of Leptospira strains isolated from livestock to 11 antibiotics. All the isolates were susceptible to penicillin, amoxicillin, clavulanate, cephalexin, ceftriaxone, doxycycline, tetracycline, streptomycin, enrofloxacin, and spectinomycin, but not polymyxin (MIC $\geq 4 \mathrm{mg} / \mathrm{L}$ ). For tetracycline and doxycycline, the MIC was significantly higher for the recent isolates from Sardinia, Italy than for the other isolates. Antimicrobial susceptibilities were also determined with 10- and 100fold-higher inocula. High inocula significantly diminished the antibacterial effect by at least ten-fold for enrofloxacin (MIC $\geq 256 \mathrm{mg} / \mathrm{L}$ ), streptomycin (MIC $\geq 16 \mathrm{mg} / \mathrm{L}$ ), and tetracycline (MIC $\geq 32 \mathrm{mg} / \mathrm{L}$ ) suggesting selection of resistant strain for high inoculum. Our findings contribute to the assessment of whether certain antibiotics are potentially useful for the treatment of leptospirosis, and point out the risk of failure for some antibiotics during infection with a high inoculum in both animals and humans. This study strengthens the need to detect and prevent the emergence of antimicrobial resistance of this major emerging zoonotic pathogen.

Keywords : Leptospira ; Leptospirosis ; Antibiotic susceptibility ; Livestock ; MIC ; High inoculum 


\section{Introduction}

Leptospirosis is the most common bacterial zoonosis worldwide, although it is most prevalent in tropical and rural environment. There are estimated to be more than one million severe cases of leptospirosis with approximately 60,000 deaths per year [1]. Its largest reservoirs are rodents which are asymptomatic carriers of pathogenic Leptospira; and contact with urine from carrier animals, often through contaminated water, is the primary route of transmission to humans. Clinical manifestations of leptospirosis are diverse, ranging from flu-like symptoms to a life-threatening hepato-renal syndrome [2]. Diagnosis of leptospirosis is often difficult because of non-specific clinical manifestations, mimicking other febrile illnesses. In addition, in many endemic areas there is poor access to reference laboratories or rapid diagnostic tests.

Suspected and confirmed cases of leptospirosis are usually treated with antibiotics $[3,4]$, using intravenous penicillin or cephalosporins of third generation for patients with severe leptospirosis and oral agents such as doxycycline or amoxicillin for milder cases. Fluoroquinolone and aminoglycoside antibiotics may also be effective. However, there is controversy over whether antibiotics decrease the severity of the disease. A review of seven randomized trials showed that the duration of the disease appeared to be shorter among patients treated with antibiotics than among those who did not receive antibiotics, but the effects on mortality were not clear [5]. In a retrospective observational study, delayed initiation of antibiotics was associated with more severe disease [6]. Although some studies in hamsters have shown a statistically significant survival advantage in the group of animals treated with antibiotics $[7,8]$, subtherapeutic use of norfloxacin and ciprofloxacin reduced the survival rate in hamsters infected with pathogenic Leptospira [10]. In C57BL/6 mice, live imaging of bioluminescent leptospires demonstrates that antibiotic treatment with penicillin, ciprofloxacin, and doxycycline is effective if administered early post-infection but failed to

81 eliminate all the leptospires from the renal tubules during the chronic phase of leptospirosis [9]. 
Leptospirosis also affects animals other than rodents and in particular food-producing animals, including livestock. The disease is therefore of economic importance. Bovine leptospirosis occurs worldwide and is caused by a wide variety of Leptospira serovars. Chronic leptospirosis in cattle is associated with abortion, stillbirth, premature birth and loss of milk production. Leptospirosis is also common in pigs can be a significant cause of reproductive loss [11]. Antibiotics are given to farm animals in order to reduce the number of infected animals, preventing, for example, abortions, and to minimize the urinary shedding and transmission between animals. A combination of penicillin and streptomycin or tetracycline have been the treatment of choice for the treatment of leptospirosis, but ampicillin and third generation cephalosporins have also been used [12].

Antibiotics are also used in agricultures for purposes other than the treatment of infections. Antibiotics are fed to food-producing animals to promote growth and improve feed efficiency. Tetracyclines, for example, have been widely used as a feed supplement. Recent projections indicate that global antimicrobial consumption in food animals will grow by at least $67 \%$ by 2030 [12], and significant fraction of this involves antimicrobials use for food production. This overuse of antibiotics in animals can contribute to the emergence of antimicrobial resistance in bacteria that may be subsequently transferred to humans [13].

Data on antimicrobial susceptibilities of Leptospira isolates are scarce. This is mainly due to the difficulty of isolating the slow-growing Leptospira from biological samples. A standardized microdilution technique has been developed for Leptospira for the assessment of antibiotic susceptibility [14]. This technique has been used for the evaluation of MIC for strains isolated from patients, rats, dogs, or swine [15-22]. These previous studies showed that Leptospira

107 strains are susceptible to current antibiotics of choice for leptospirosis treatment but resistant

108 to trimethoprim, sulfamethoxazole, and neomycin; these findings allowed the development of

109 a new selective medium for the isolation of Leptospira, preventing growth of contaminants 110 [23]. 
111 In the current context of antibiotic pressure and regular chronic infections, monitoring of

112 Leptospira strains in livestock may help detect the emergence of antimicrobial resistance.

113 The aim of this study was to evaluate the antibiotic susceptibility of Leptospira strains

114 isolated from livestock and help in the identification of resistant strains when isolates grow at

115 antibiotic concentrations higher than the range seen for wild-type strains.

116

117 


\section{Materials and Methods}

119 2.1. Strains and culture conditions

120 Leptospira strains were selected from the collection of the "Biology of Spirochetes" unit which 121 comprises reference strains and strains received at the French National Reference Center 122 for Leptospirosis (Institut Pasteur, Paris) for identification and characterization. Other strains 123 were obtained from Sardinia, Italy (N. Ponti, Istituto Zooprofilattico Sperimentale della

124 Sardegna, Sassari, Italy) and Uruguay (A. Buschiazzo, on behalf of the multicentric 125 consortium Grupo de Trabajo Interinstitucional de Leptospirosis, Institut Pasteur 126 Montevideo/UdelaR/INIA/MGAP, Uruguay).. Strains were cultivated in in-house made liquid 127 Ellinghausen-McCullough-Johnson-Harris (EMJH) medium or on $1 \%$ agar plates at $30^{\circ} \mathrm{C}$. 128 Isolates were characterized by $16 \mathrm{~S}$ rRNA sequencing and microscopic agglutination test 129 (MAT) using a standard battery of rabbit antisera against reference serovars representing 24 130 serogroups. Our final collection was composed of 35 Leptospira strains, representing six 131 species and nine serogroups (Table 1). The strains were isolated from cattle (19 strains), 132 swine (10 strains), donkey (one strain), deer (one strain), and human patients (3 strains; 133 associated with contact with cattle and/or prevalent in cattle) between 1936 and 2016 and 134 came from different areas: Europe (13 strains), South America (11 strains), Asia and 135 Oceania (6 strains) and United States (3 strains).

\section{$137 \quad$ 2.2. Antibiotics}

138 Penicillins (penicillin G, amoxicillin, clavulanate), first and third generation cephalosporin 139 (cephalexin, ceftriaxone), aminoglycosides (streptomycin, spectinomycin), cyclines 140 (tetracycline, doxycycline), fluoroquinolone (ernofloxacin) and polypeptide (polymyxin E) 141 were purchased from Sigma-Aldrich. All but ceftriaxone which is used as a therapeutic in

142 humans are used in farms. Antibiotics were stocked in a stock solution at a concentration of $14325 \mathrm{mg} / \mathrm{mL}$ according to the manufacturer's suggestions. The stock solutions of antibiotics 144 were preserved at $4^{\circ} \mathrm{C}$ and renewed every two weeks. 


\subsection{MIC Determination}

147 The MIC was determined for all antibtiotics by the broth microdilution method described by 148 Murray and Hospenthal [14]. Briefly, exponential-phase cultures of Leptospira were counted 149 in a Petroff-Hausser counting chamber (Fisher Scientific) and Leptospira was deposited at a 150 final concentration of $2 \times 10^{6}$ leptospires $/ \mathrm{mL}$ in each well of 96 well plates (Techno Plastic 151 Product) with serial two-fold dilutions of antibiotics ranging from 32 to $0.016 \mathrm{mg} / \mathrm{L}$ in EMJH 152 media; the final volume in each well was $200 \mu \mathrm{L}$. The plates were incubated for 3 days at $15330^{\circ} \mathrm{C}$, then $20 \mu \mathrm{l}$ of Alamar Blue ${ }^{\circledR}$ (Invitrogen, Thermo Fisher Scientific) was added in each 154 well and the samples incubated at $30^{\circ} \mathrm{C}$ for 2 days: any change in color from blue to pink was considered to indicate cell growth. The minimal inhibitory concentration (MIC) was recorded as the concentration in the well containing the lowest concentration without a blue to pink color change. Each strain-drug combination was tested in duplicate and positive

158 (bacteria and no antibiotic added) and negative (no bacteria added) controls were included in 159 each plate. We also determined MICs for two strains with inocula $10^{-1}-, 10$ - and 100 -times

160 the standard Leptospira cell density to evaluate the inoculum effect : thus, inocula of $2 \times 10^{5}$, $1612 \times 10^{7}$, and $2 \times 10^{8}$ Leptospira $/ \mathrm{ml}$ were tested as described above. These strains are two representative strains of our collection for which we can obtain high cell density cultures (>

$16310^{8}$ leptospires $\left./ \mathrm{mL}\right)$.

\subsection{Statistical analysis}

166 Strain characteristics in this study were described using frequencies and medians with

167 interquartile (IQR) ranges. Univariable linear regression analysis was conducted to investigate factors associated with an increase of MIC compare. Odds ratios (OR) with 95\% confidence intervals $[95 \% \mathrm{Cl}]$ were calculated. Statistical significance was defined as a P-

170 value $<0.05$ (two-tailed). Statistical analyses were performed with the $R$ version $3.1 .2(R$

171 Foundation for Statistical Computing, Vienna, Austria). 


\section{Results}

\subsection{Antibiotic susceptibility}

177 MICs to 11 diverse antimicrobial agents were determined. They include penicillins (penicillin G, amoxicillin, clavulanate), first and third generation cephalosporins (cephalexin,

179 ceftriaxone), aminoglycosides (streptomycin, spectinomycin), cyclines (tetracycline,

180 doxycycline), fluoroquinolone (ernofloxacin) and polypeptide (polymyxin E). Distribution and 181 median MIC are reported in Figure S1 and Table 2.

182 All strains were susceptible to amoxicillin, clavulanate and cefalexin with median MICs of 1830.02 (IQR [0.02-0.03]), 0.5 (IQR [0.25-0.5]) and $4 \mathrm{mg} / \mathrm{L}$ (IQR [3-4]), respectively. Strains were generally very susceptible to penicillin $\mathrm{G}$ with a median MIC of $0.06 \mathrm{mg} / \mathrm{L}$ (IQR [0.03-0.12]) although one strain recently isolated from swine in Sardinia $\left(\mathrm{N}^{\circ} 21\right)$ had a MIC of $1 \mathrm{mg} / \mathrm{L}$; this strain and a strain isolated in the United States $\left(\mathrm{N}^{\circ} 18\right)$ had a high ceftriaxone MIC of $1 \mathrm{mg} / \mathrm{L}$. All the others strains were very susceptible to ceftriaxone. Five of the eight strains recently isolated in Sardinia had a high MIC for cyclines; three strains had a tetracyline MIC of $4 \mathrm{mg} / \mathrm{L}$ $\left(\mathrm{N}^{\circ} 20, \mathrm{~N}^{\circ} 21, \mathrm{~N}^{\circ} 22\right)$; one strain had a doxycycline MIC of $2 \mathrm{mg} / \mathrm{L}\left(\mathrm{N}^{\circ} 26\right)$ and one strain had both tetracycline MIC of $4 \mathrm{mg} / \mathrm{L}$ and a doxycycline MIC of $2 \mathrm{mg} / \mathrm{L}\left(\mathrm{N}^{\circ} 7\right)$. One strain recently isolated from cattle in Uruguay also had a tetracycline MIC of $4 \mathrm{mg} / \mathrm{L}\left(\mathrm{N}^{\circ} 27\right)$. The medians MIC for enrofloxacin was $1 \mathrm{mg} / \mathrm{L}(\mathrm{IQR}[0.5-1])$ and no strains had a MIC above to $1 \mathrm{mg} / \mathrm{L}$.

193 Spectinomycin and streptomycin were effective against all isolates. All the strains seemed to

194 be naturally resistant to polymyxin B with a median MIC of $8 \mathrm{mg} / \mathrm{L}$ (IQR [4-8]), which is higher than the MIC breakpoint of this antibiotic (24).

\subsection{Factors associated with high MIC in Leptospira isolates}

198 In univariate analysis, susceptibility to antibiotics was generally similar for the three main

199 species of Leptospira (Table 3 ). Although L. interrogans had lower MIC to clavulanate than 200 the others strains $(\mathrm{OR}=0.8,95 \%$ IC $[0,6-0,9])$, the overall susceptibility to antibiotics of 201 Leptospira strains was independent of the species. MICs to streptomycin (OR=4.3, 95\% IC 
[1.4-13.1]) and polymyxin (OR=610, 95\% IC [43.9-8466.6]) were higher in strains isolated from swine than cattle (Table 3). Median MICs did not differ greatly according to the continent of isolation (Table 3). Strains isolated in 2016 presented higher MICs for tetracycline $(\mathrm{OR}=4.0,95 \% \mathrm{IC}[1.8-8.7]$ and spectinomycin $(\mathrm{OR}=24.1,95 \% \mathrm{IC}[2-295.6])$ than strains isolated earlier (Table 3). The pooled MIC to cyclines of the Sardinia strains is 2.8 times higher than the others strains $(\mathrm{OR}=2.8,95 \% \mathrm{Cl}[1.8-4.5])$ (Figure 1) and was very close to the MIC breakpoint of cyclines (24). In total, five strains isolated form Sardinia $\left(\mathrm{N}^{\circ} 7\right.$, $\mathrm{N}^{\circ} 20, \mathrm{~N}^{\circ} 21, \mathrm{~N}^{\circ} 22, \mathrm{~N}^{\circ} 26$ ) and one from Uruguay showed decreased susceptibility to cyclines (Table S1).

\subsection{Impact of high inoculum density on antibiotic susceptibility}

213 To further investigate the effectiveness of antibiotics, we also determined MICs with lower 214 and higher inocula (from $2 \times 10^{5}$ to $2 \times 10^{8}$ Leptospira per $\mathrm{mL}$ ) for two representative strains or 215 our collection (Table 4). The observed MIC of most antibiotics increased with inoculum 216 density. Amoxicillin was the only antibiotic for which the size of the inoculum had no impact 217 on MIC values. The MICs of other beta-lactams increased gradually with inoculum density, 218 but remained below the MIC breakpoint of these antibiotics (24) suggesting effectiveness 219 even for large inocula. The MICs of doxycycline and tetracycline were at least 8-fold higher 220 for inoculum densities of $2 \times 10^{7}$ bacteria per $\mathrm{mL}$ or more than for the standard inoculum. The 221 MICs of enrofloxacin, streptomycin and spectinomycin were higher for high inocula: in 222 particular the MICs of enrofloxacin and streptomycin were $\geq 256 \mathrm{mg} / \mathrm{L}$ at an inoculum of $2232 \times 10^{8}$ Leptospira per $\mathrm{mL}$. This pattern differs from that for cephalexin, ceftriaxone, polymyxin, 224 penicillin, clavulanate, and spectinomycin for which the MICs increased only slowly with inoculum density (Table 4 ).

\section{Discussion}

228 Veterinary use of antimicrobials is believed to contribute to the emergence of antimicrobial229 resistant strains. Pathogenic Leptospira is responsible for chronic infections in livestock 
230 leading to abortions and other reproduction disorders. Some serovars are particularly 231 associated with chronic infection, for example Hardjobovis in cattle and Pomona in swine. 232 Re-infections of animals in the same farm are frequent [11]. There is currently no 233 comprehensive data about the antibiotic susceptibility of Leptospira strains in farm animals.

234 Evaluating the antibiotic susceptibility of Leptospira strains in livestock provides a baseline 235 for monitoring trends in antimicrobial resistance in this species. We therefore analyzed 236 susceptibilities of strains isolated worldwide over an 80-year period to the antibiotics most 237 commonly used in veterinary medicine. Our findings are consistent with prior reports of 238 Leptospira susceptibility to penicillin, amoxicillin, cephalexin, ceftriaxone, doxycycline, 239 tetracycline, streptomycin, spectinomycin, and polymyxin [18-20,25]. Previous studies 240 showed low enrofloxacin and its active metabolite ciprofloxacin MIC values ( $\leq 0.6 \mathrm{mg} / \mathrm{L})[15$, 241 17-19], but most of our isolates showed a MIC of $1 \mathrm{mg} / \mathrm{L}$. Similarly, L. interrogans serovar 242 Pomona isolates from swine in Brazil were found to be resistant to fluoroquinolones 243 (enrofloxacin MIC > 4mg/L) [26]. We report the good in vitro susceptibility of Leptospira 244 strains to the beta-lactamase inhibitor clavulanate (IQR [0.25-0.5]) and this is a novel finding. 245 MICs were not significantly different between Leptospira species, sources (cattle, swine or 246 others), or place of isolation (countries and continents). However, the MICs were higher for 247 the most recent isolates; mostly recovered from Sardinia in Italy. Strains isolated in Sardinia 248 had high MICs to cyclines. Similar pattern of resistance has been observed on isolates from 249 patients in Egypt [18]; the authors suggested that the substantial exposure of the population 250 to cyclines in this country might explain the high MIC values. We also report one strain (strain 251 21) with high MICs for ceftriaxone and penicillin G. This resistance profile has already been 252 described in an L. interrogans strain isolated from rats in the Philippines [19]. The killing rate 253 of the antibiotics declined with the cell density, but the MICs, for example of beta-lactams, 254 remained below the MIC breakpoint [24], consistent with good efficacy. Amoxicillin presented 255 the lowest MICs in our study and its efficacy was independent of the inoculum size, 256 suggesting that amoxicillin might be a treatment of choice for leptospirosis. In contrast, high 257 inoculum density significantly diminished (at least 10-fold increase of MIC) the antibacterial 
258 effects of tetracycline, enrofloxacin, and streptomycin. This inoculum effect may possibly be

259 the consequence of selection and proliferation of spontaneous resistant mutants for these

260 antibiotics in large inocula. However, the inoculum effect is an in vitro laboratory

261 phenomenon and should be interpreted with caution. Trailing end points may be seen when

262 bacteriostatic antibiotics such as tetracycline are tested. Nevertheless, our observations suggest that these antibiotics may not be the most reliable agents for therapy in cases of

264 high bacterial load Leptospira infections. In animal models Leptospira can reach peaks of $10^{8}$ leptospires per gram or per milliliter in blood and all tissues after intraperitoneal inoculation with pathogenic strains [27]. The bacterial load in the blood of patients can exceed $10^{6}$ leptospires $/ \mathrm{mL}$, and such high loads are usually associated with poor outcomes [28-30]. Leptospira can also form biofilms with high cell densities [31] that can resist antibiotic treatment [32], thereby reducing the effectiveness of antimicrobial drugs for treating human disease. The standard method for assessing the in vitro activity of antimicrobial agents

271 against Leptospira species might not be efficient for predicting the therapeutic efficacy of 272 antibiotics.

274 Further genomic exploration is required to elucidate the molecular mechanisms responsible for antimicrobial resistance in Leptospira. Only very few plasmids have been isolated so far in pathogenic Leptospira and they do not carry genes conferring resistance [33,34]. In

277 addition, Leptospira are not naturally competent for transformation. The ability of Leptospira 278 to acquire resistance genes such as modifying- or degrading-enzymes by horizontal transfer 279 is thus probably limited. Alteration in the target sites of antibiotics may therefore be the major 280 cause of antibiotic resistance in Leptospira. It has been shown experimentally that in vitro 281 selection can result in the development of resistance to spectinomycin and streptomycin in 282 Leptospira due to spontaneous mutation of the target gene 16S rRNA and rpsL, respectively $283[35,36]$. 
285 It would be useful to analyze a larger collection of Leptospira strains of different origins to 286 determine more precisely the epidemiological cut-off (ECOFF) value which is the MIC value 287 at the upper limit of the wild-type population [37]. This is particularly important because there 288 is actually no clearly established correlation between clinical breakpoints and clinical 289 outcome of antimicrobial agents in leptospirosis.

\section{Conclusion}

294 There appears to be a heterogeneity of MICs to some antibiotics among Leptospira strains isolated from food-producing animals of diverse geographical origins between 1936 and 2016. Substantial inoculum effects on efficacy were also observed for at least five antibiotics and point out the risk of failure for some antibiotics during infection with high inoculum in both animals and humans. Additional studies are required to better discriminate between susceptible and resistant Leptospira strains.

\section{Acknowledgments}

We thank the consortium "Grupo de Trabajo Interinstitucional de Leptospirosis" (Institut

303 Pasteur Montevideo/UdelaR/INIA/MGAP, Uruguay) and Nicoletta Ponti for providing

304 Leptospira strains. Thanks are also due to the technicians of the French National Reference

305 Center for Leptospirosis for culture and identification of strains.

\section{Declarations}

308 Funding: This work was supported by a grant from French ministry of health (Agence 309 régionale de Santé of Guadeloupe) to G.L. and by Institut Pasteur and Santé Publique 310 France (Centre National de Référence de la Leptospirose). 
311 Competing interests: No conflict

312 Ethical Approval: Not required

\section{Appendix: Supplementary data}

\section{References}

318 [1] Costa F, Hagan JE, Calcagno J, Kane M, Torgerson P, Martinez-Silveira MS, et al. 319 Global Morbidity and Mortality of Leptospirosis: A Systematic Review. PLoS Negl Trop Dis 320 2015;9:e0003898. doi:10.1371/journal.pntd.0003898.

321 [2] Levett PN. Leptospirosis. Clin Microbiol Rev 2001;14:296-326. 322 doi:10.1128/CMR.14.2.296-326.2001.

323 [3] Bharti AR, Nally JE, Ricaldi JN, Matthias MA, Diaz MM, Lovett MA, et al. 324 Leptospirosis: a zoonotic disease of global importance. Lancet Infect Dis 2003;3:757-71.

325 [4] Griffith ME, Hospenthal DR, Murray CK. Antimicrobial therapy of leptospirosis. Curr 326 Opin Infect Dis 2006;19:533-7. doi:10.1097/QCO.0b013e3280106818.

327 [5] Brett-Major DM, Coldren R. Antibiotics for leptospirosis. Cochrane Database Syst Rev 328 2012:CD008264. doi:10.1002/14651858.CD008264.pub2.

329 [6] Tubiana S, Mikulski M, Becam J, Lacassin F, Lefèvre P, Gourinat A-C, et al. Risk

330 factors and predictors of severe leptospirosis in New Caledonia. PLoS Negl Trop Dis $331 \quad$ 2013;7:e1991. doi:10.1371/journal.pntd.0001991.

332 [7] Griffith ME, Moon JE, Johnson EN, Clark KP, Hawley JS, Hospenthal DR, et al. 333 Efficacy of fluoroquinolones against Leptospira interrogans in a hamster model. Antimicrob 334 Agents Chemother 2007;51:2615-7. doi:10.1128/AAC.00240-07.

335 [8] Truccolo J, Charavay F, Merien F, Perolat P. Quantitative PCR assay to evaluate 336 ampicillin, ofloxacin, and doxycycline for treatment of experimental leptospirosis. Antimicrob 337 Agents Chemother 2002;46:848-53. 
338 [9] Ratet G, Veyrier FJ, Fanton d'Andon M, Kammerscheit X, Nicola M-A, Picardeau M, 339 et al. Live imaging of bioluminescent leptospira interrogans in mice reveals renal colonization 340 as a stealth escape from the blood defenses and antibiotics. PLoS Negl Trop Dis $341 \quad$ 2014;8:e3359. doi:10.1371/journal.pntd.0003359.

342 [10] Wu D, Zhang W, Wang T, Lin T, Jin X, Xie X, et al. Low-dose norfloxacin and 343 ciprofloxacin therapy worsen leptospirosis in hamster. Microb Pathog 2017;102:36-41. 344 doi:10.1016/j.micpath.2016.11.018.

345 [11] Ellis WA. Animal Leptospirosis. In: Adler B, editor. Leptospira and Leptospirosis, 346 ,Springer Berlin Heidelberg, 2015, p. 99-138

347 [12] Van Boeckel TP, Brower C, Gilbert M, Grenfell BT, Levin SA, Robinson TP, et al. 348 Global trends in antimicrobial use in food animals. Proc Natl Acad Sci U S A 2015;112:5649_ 349 54. doi:10.1073/pnas. 1503141112.

350 [13] Silbergeld EK, Graham J, Price LB. Industrial food animal production, antimicrobial 351 resistance, and human health. Annu Rev Public Health 2008;29:151-69. 352 doi:10.1146/annurev.publhealth.29.020907.090904.

353 [14] Murray CK, Hospenthal DR. Broth microdilution susceptibility testing for Leptospira 354 spp. Antimicrob Agents Chemother 2004;48:1548-52.

355 [15] Murray CK, Hospenthal DR. Determination of susceptibilities of 26 Leptospira sp. 356 serovars to 24 antimicrobial agents by a broth microdilution technique. Antimicrob Agents 357 Chemother 2004;48:4002-5. doi:10.1128/AAC.48.10.4002-4005.2004.

358 [16] Hospenthal DR, Murray CK. In vitro susceptibilities of seven Leptospira species to 359 traditional and newer antibiotics. Antimicrob Agents Chemother 2003;47:2646-8.

360 [17] Kim D, Kordick D, Divers T, Chang YF. In vitro susceptibilities of Leptospira spp. and 361 Borrelia burgdorferi isolates to amoxicillin, tilmicosin, and enrofloxacin. J Vet Sci 2006;7:3553629.

363 [18] Ressner RA, Griffith ME, Beckius ML, Pimentel G, Miller RS, Mende K, et al. 364 Antimicrobial Susceptibilities of Geographically Diverse Clinical Human Isolates of 365 Leptospira. Antimicrob Agents Chemother 2008;52:2750-4. doi:10.1128/AAC.00044-08. 
366 [19] Chakraborty A, Miyahara S, Villanueva SYAM, Gloriani NG, Yoshida S-I. In vitro 367 sensitivity and resistance of 46 Leptospira strains isolated from rats in the Philippines to 14 368 antimicrobial agents. Antimicrob Agents Chemother 2010;54:5403-5. 369 doi:10.1128/AAC.00973-10.

370 [20] Suepaul SM, Carrington C, Campbell M, Borde G, Adesiyun AA. Antimicrobial 371 susceptibility of Leptospira isolates from dogs and rats to 12 antimicrobial agents. Trop 372 Biomed 2015;32:1-10.

373 [21] Benacer D, Zain SNM, Ooi PT, Thong KL. Antimicrobial susceptibility of Leptospira 374 spp. isolated from environmental, human and animal sources in Malaysia. Indian J Med 375 Microbiol 2017;35:124-8. doi:10.4103/ijmm.IJMM_15_458.

376 [22] Miraglia F, Matsuo M, Morais ZM, Dellagostin OA, Seixas FK, Freitas JC, et al. 377 Molecular characterization, serotyping, and antibiotic susceptibility profile of Leptospira 378 interrogans serovar Copenhageni isolates from Brazil. Diagn Microbiol Infect Dis 379 2013;77:195-9. doi:10.1016/j.diagmicrobio.2013.08.003.

380 [23] Chakraborty A, Miyahara S, Villanueva SYAM, Saito M, Gloriani NG, Yoshida S-I. A 381 novel combination of selective agents for isolation of Leptospira species. Microbiol Immunol 382 2011;55:494-501. doi:10.1111/j.1348-0421.2011.00347.x.

383 [24] EUCAST: Clinical breakpoints n.d. http://www.eucast.org/clinical_breakpoints/ 384 (accessed July 25, 2017).

385 [25] Harris BM, Blatz PJ, Hinkle MK, McCall S, Beckius ML, Mende K, et al. In vitro and in 386 vivo activity of first generation cephalosporins against Leptospira. Am J Trop Med Hyg 387 2011;85:905-8. doi:10.4269/ajtmh.2011.11-0352.

388 [26] Miraglia F, Moreno AM, Gomes CR, Paixão R, Liuson E, Morais ZM, et al. Isolation 389 and characterization of Leptospira interrogans from pigs slaughtered in São Paulo State, 390 Brazil. Braz J Microbiol Publ Braz Soc Microbiol 2008;39:501-7. doi:10.1590/S1517391838220080003000017.

392 [27] Wunder EA, Figueira CP, Santos GR, Lourdault K, Matthias MA, Vinetz JM, et al. 393 Real-Time PCR Reveals Rapid Dissemination of Leptospira interrogans after Intraperitoneal 
394 and Conjunctival Inoculation of Hamsters. Infect Immun 2016;84:2105-15. 395 doi:10.1128/IAI.00094-16.

396 [28] Hochedez P, Theodose R, Olive C, Bourhy P, Hurtrel G, Vignier N, et al. Factors 397 Associated with Severe Leptospirosis, Martinique, 2010-2013. Emerg Infect Dis $398 \quad$ 2015;21:2221-4. doi:10.3201/eid2112.141099.

399 [29] Segura ER, Ganoza CA, Campos K, Ricaldi JN, Torres S, Silva H, et al. Clinical 400 spectrum of pulmonary involvement in leptospirosis in a region of endemicity, with 401 quantification of leptospiral burden. Clin Infect Dis Off Publ Infect Dis Soc Am 2005;40:343402 51. doi: $10.1086 / 427110$.

403 [30] Truccolo J, Serais O, Merien F, Perolat P. Following the course of human 404 leptospirosis: evidence of a critical threshold for the vital prognosis using a quantitative PCR 405 assay. FEMS Microbiol Lett 2001;204:317-21.

406 [31] Ristow P, Bourhy P, Kerneis S, Schmitt C, Prevost M-C, Lilenbaum W, et al. Biofilm 407 formation by saprophytic and pathogenic leptospires. Microbiol Read Engl 2008;154:1309_ 408 17. doi:10.1099/mic.0.2007/014746-0.

409 [32] Vinod Kumar K, Lall C, Raj RV, Vedhagiri K, Sunish IP, Vijayachari P. In Vitro 410 Antimicrobial Susceptibility of Pathogenic Leptospira Biofilm. Microb Drug Resist Larchmt N $411 \quad 2016 ; 22: 511-4$. doi:10.1089/mdr.2015.0284.

412 [33] Zhu W-N, Huang L-L, Zeng L-B, Zhuang X-R, Chen C-Y, Wang Y-Z, et al. Isolation 413 and characterization of two novel plasmids from pathogenic Leptospira interrogans 414 serogroup Canicola Serovar Canicola strain Gui44. PLoS Negl Trop Dis 2014;8:e3103. 415 doi:10.1371/journal.pntd.0003103.

416 [34] Wang Y, Zhuang X, Zhong Y, Zhang C, Zhang Y, Zeng L, et al. Distribution of 417 Plasmids in Distinct Leptospira Pathogenic Species. PLoS Negl Trop Dis 2015;9:e0004220. 418 doi:10.1371/journal.pntd.0004220.

419 [35] Poggi D, Oliveira de Giuseppe P, Picardeau M. Antibiotic resistance markers for 420 genetic manipulations of Leptospira spp. Appl Environ Microbiol 2010;76:4882-5. 421 doi:10.1128/AEM.00775-10. 
422 [36] Fukunaga M, Mifuchi I. Mechanism of streptomycin resistance in Leptospira biflexa 423 strain Urawa. Microbiol Immunol 1988;32:641-4.

424 [37] Turnidge J, Kahlmeter G, Kronvall G. Statistical characterisation of bacterial wild-type 425 MIC value distributions and the determination of epidemiological cut-off values. Clin Microbiol 426 Infect Off Publ Eur Soc Clin Microbiol Infect Dis 2006;12:418-25. doi:10.1111/j.1469$427 \quad 0691.2006 .01377 . x$.

\section{Figure 1. Box plot of MIC for cyclines for strains isolated in Italy (Sardinia)}

431 MICs of strains isolated in Sardinia, Italy was compared with other strains for cyclines, 432 including pooled MICs for doxycycline and tetracycline (A) and individually for each antibiotic 433 doxycycline (Doxy) and Tetracycline (Tetra) (B).

434 Boxes encompass all data points between the 25th and 75th percentiles (interquartile range, 435 (QR). Thick bars in boxes indicate the median data value. The vertical bar indicates the 436 maximum/minimum values. Data points outside this range ('outliers') are plotted individually 437 as dots. 

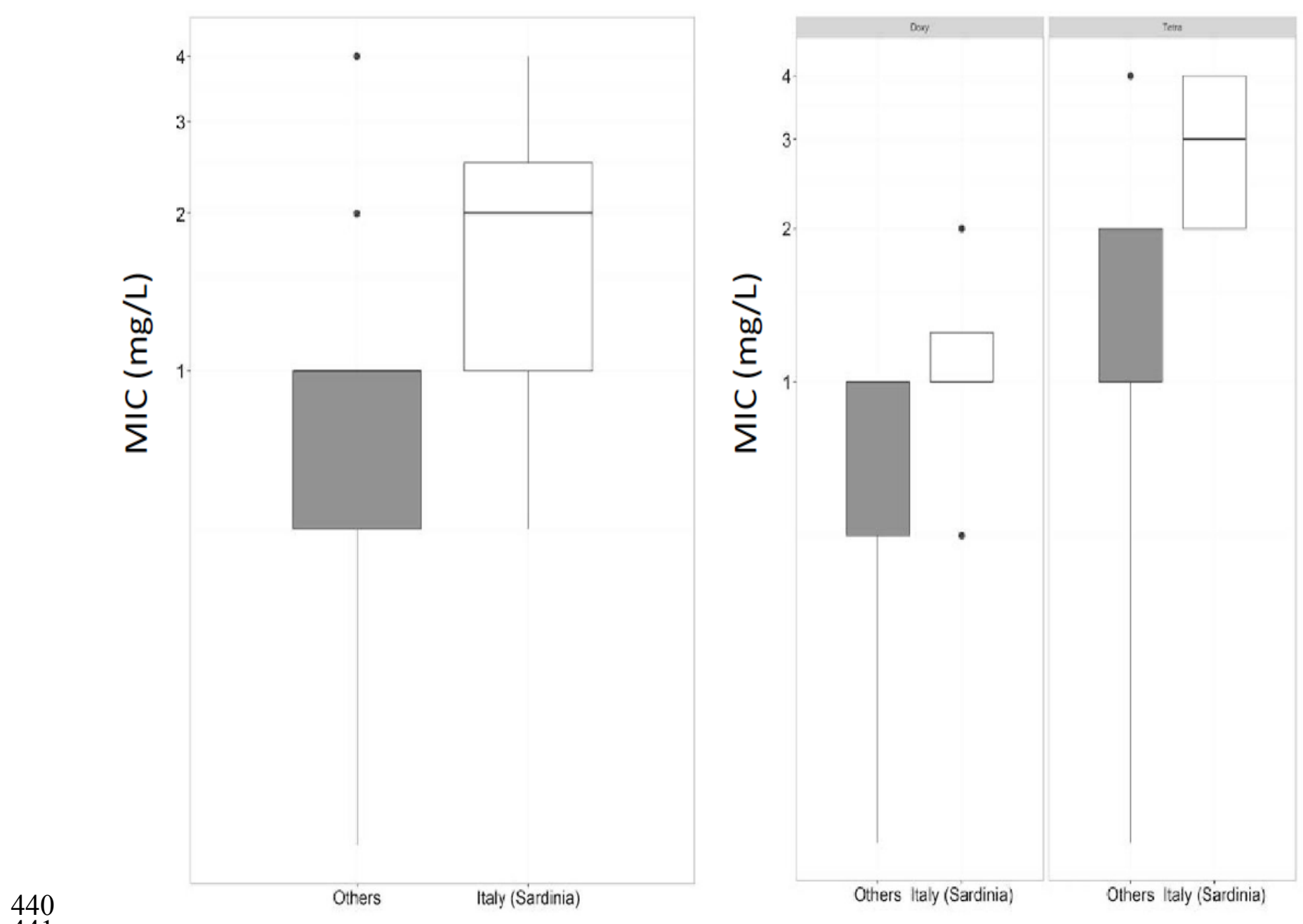


\section{Tables}

Table 1. Leptospira strains used in this study

\begin{tabular}{|c|c|c|c|c|c|c|}
\hline Strains & Species & Source & Serogroups & Location & \begin{tabular}{|c|}
$\begin{array}{c}\text { Isolation } \\
\text { date }\end{array}$ \\
\end{tabular} & Strains \\
\hline 1 & L. borgpetersenii & Swine & Tarrassovi & Brazil & 1948 & RP29 \\
\hline 2 & L. borgpetersenii & Cattle & Sejroe & England & 1980 & Hardjo \\
\hline 3 & L. borgpetersenii & Human $^{1}$ & Sejroe & Australia & 1999 & L550 \\
\hline 4 & L. borgpetersenii & Swine & Tarrassovi & Brazil & 1993 & PC 10 \\
\hline $5^{2}$ & L. borgpetersenii & Cattle & Sejroe & Uruguay & 2016 & IP1512012 \\
\hline 6 & L. borgpetersenii & Swine & Tarrassovi & China & 1986 & L100 \\
\hline 7 & L. borgpetersenii & Swine & Tarrassovi & Italy & 2015 & 27562 \\
\hline 8 & L. borgpetersenii & Cattle & Sejroe & Spain & 2000 & P399 \\
\hline 9 & L. broomii & $\begin{array}{l}\text { Breeding } \\
\text { deer }\end{array}$ & Unknown & $\begin{array}{c}\text { New } \\
\text { Caledonia }\end{array}$ & 1988 & 10840 \\
\hline 10 & L. interrogans & Swine & Unknown & Brazil & 1993 & PC 33 \\
\hline 11 & L. interrogans & Cattle & Pomona & USA & 1965 & 164 \\
\hline 12 & L. interrogans & Human $^{1}$ & Sejroe & Indonesia & 1938 & Hardjoprajitno \\
\hline 13 & L. interrogans & Cattle & Sejroe & Ireland & 1980 & S.80.1441 \\
\hline 14 & L. interrogans & Swine & Pomona & Croatia & 2002 & 200205138 \\
\hline 15 & L. interrogans & Human $^{1}$ & Pomona & Australia & 1936 & Pomona \\
\hline 16 & L. interrogans & Swine & Pomona & $\begin{array}{c}\text { New } \\
\text { Caledonia }\end{array}$ & 1991 & LTDV 5 \\
\hline 17 & L. interrogans & Cattle & Australis & Spain & 2000 & P399 \\
\hline 18 & L. interrogans & Cattle & Pomona & $\begin{array}{l}\text { USA } \\
\text { New }\end{array}$ & 1964 & LT1026 \\
\hline 19 & L. interrogans & Cattle & Pomona & Caledonia & 1988 & D10613 \\
\hline 20 & L. interrogans & Cattle & Unknown & Italy & 2016 & $75022-5$ \\
\hline 21 & L. interrogans & Swine & Unknown & Italy & 2016 & $71516-5$ \\
\hline 22 & L. interrogans & Swine & Pomona & Italy & 2016 & $71516-1$ \\
\hline 23 & L. interrogans & Cattle & Pomona & Italy & 2016 & $77219-2$ \\
\hline 24 & L. interrogans & Cattle & Pomona & Italy & 2016 & $77219-3$ \\
\hline 25 & L. interrogans & Cattle & Pomona & Italy & 2016 & $77219-4$ \\
\hline 26 & L. interrogans & Donkey & Pomona & Italy & 2016 & 85282 \\
\hline $27^{2}$ & L. interrogans & Cattle & Pomona & Uruguay & 2016 & IP1507003 \\
\hline 28 & L. kirschneri & Cattle & Canicola & Argentina & 1969 & LT1014 \\
\hline 29 & L. kirschneri & Cattle & Grippotyphosa & Turkey & 1990 & Daclas 1 \\
\hline 30 & L. noguchii & Cattle & Panama & Brazil & 2013 & U73 \\
\hline 31 & L. noguchii & Cattle & Australis & Peru & 1962 & V42 \\
\hline $32^{2}$ & L. noguchii & Cattle & Unknown & Uruguay & 2016 & IP1512017 \\
\hline $33^{2}$ & L. noguchii & Cattle & Pyrogenes & Uruguay & 2016 & IP1605021 \\
\hline $34^{2}$ & L. noguchii & Cattle & Australis & Uruguay & 2016 & IP1611024 \\
\hline 35 & L. santarosai & Cattle & Mini & USA & 1974 & Oregon \\
\hline
\end{tabular}


${ }^{1}$ Strains isolated from human after close contact with cattle breeding animals, ${ }^{2}$ Species identification and serogrouping communicated by the Grupo de Trabajo Interinstitucional de Leptospirosis (Uruguay) (manuscript under preparation).

Table 2. Distribution of MIC for 11 antimicrobial agents among the 35 Leptospira strains.

\begin{tabular}{|c|c|c|c|c|c|c|c|c|c|c|c|c|}
\hline \multirow{2}{*}{ Antimicrobial agent } & \multicolumn{11}{|c|}{ No. of strains with MIC (mg/L) of: } & \multirow{2}{*}{ Median MIC [IQR] } \\
\hline & $<0.016$ & 0.032 & 0.064 & 0.125 & 0.25 & 0.5 & 1 & 2 & 4 & 8 & 16 & \\
\hline Penicillin & 3 & 7 & 13 & 6 & 4 & 1 & 1 & & & & & $0.06[0.03-0.12]$ \\
\hline Amoxicillin & 24 & 8 & 3 & & & & & & & & & $0.02[0.02-0.03]$ \\
\hline Clavulanate & & & & 2 & 9 & 21 & 3 & & & & & $0.5[0.25-0.5]$ \\
\hline Cephalexin & & & & & & & 1 & 8 & 24 & 2 & & $4[3-4]$ \\
\hline Ceftriaxone & & 2 & 4 & 13 & 8 & 6 & 2 & & & & & $0.12[0.12-0.25]$ \\
\hline Doxycycline & & & & 1 & 3 & 11 & 18 & 2 & & & & 1 [0.5-1] \\
\hline Tetracycline & & & & 1 & & 5 & 9 & 15 & 5 & & & $2[1-2]$ \\
\hline Enrofloxacin & & & & 2 & 3 & 12 & 18 & & & & & $1[0.5-1]$ \\
\hline Spectinomycin & & & & & & & 2 & 12 & 8 & 11 & 2 & $4[2-8]$ \\
\hline Streptomycin & & & & & & 4 & 7 & 16 & 7 & 1 & & $2[1-2]$ \\
\hline Polymyxin E & & & & & & & & 1 & 10 & 17 & 7 & 8 [4-8] \\
\hline
\end{tabular}




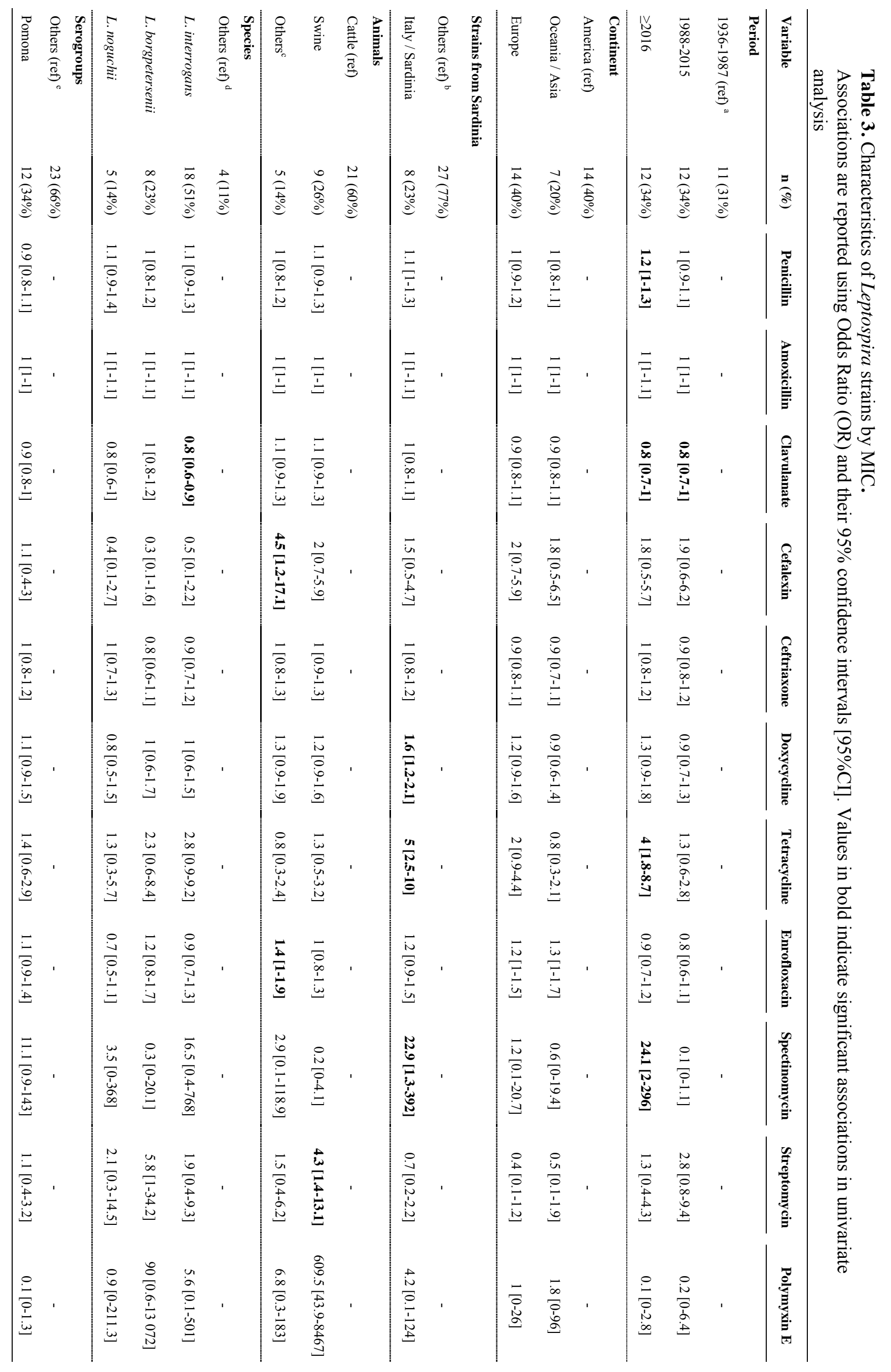




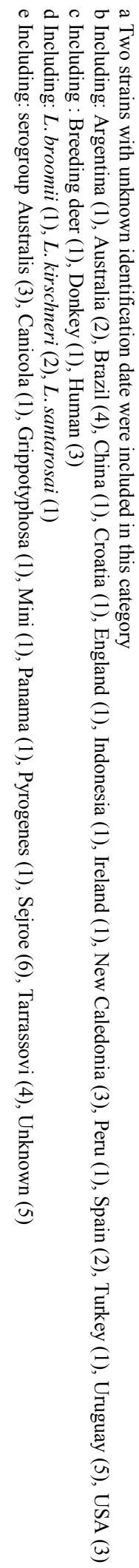


Table 4. Variation of MIC according to the size of the inoculum

\begin{tabular}{|c|c|c|c|c|c|c|c|c|}
\hline \multirow{3}{*}{ Antibiotics } & \multicolumn{8}{|c|}{ Concentration of Leptospira (bacteria per $\mathrm{mL}$ ) } \\
\hline & \multicolumn{4}{|c|}{ L. borgpetersenii (strain $\left.n^{\circ} 6\right)$} & \multicolumn{4}{|c|}{ L. noguchi (strain $\mathrm{n}^{\circ} 34$ ) } \\
\hline & $2 \times 10^{5}$ & $2 \times 10^{6}$ & $2 \times 10^{7}$ & $2 \times 10^{8}$ & $2 \times 10^{5}$ & $2 \times 10^{6}$ & $2 \times 10^{7}$ & $2 \times 10^{8}$ \\
\hline Penicillin & 0.016 & 0.032 & 0.125 & 0.25 & 0.125 & 0.25 & 0.5 & 1 \\
\hline Amoxicillin & $<0.016$ & $<0.016$ & $<0.016$ & $<0.016$ & $<0.016$ & $<0.016$ & $<0.016$ & $<0.016$ \\
\hline Clavulanate & 0.25 & 0.5 & 1 & 4 & 0.25 & 0.5 & 2 & 4 \\
\hline Cephalexin & 2 & 4 & 8 & 16 & 2 & 4 & 8 & 16 \\
\hline Ceftriaxone & 0.064 & 0.125 & 0.25 & 0.5 & 0.125 & 0.5 & 0.5 & 1 \\
\hline Doxycycline & 0.5 & 1 & 8 & 16 & 0.25 & 0.5 & 4 & 16 \\
\hline Tetracycline & 0.5 & 1 & 32 & 64 & 0.5 & 2 & 8 & 64 \\
\hline Enrofloxacin & 0.25 & 0.5 & 256 & 512 & 0.25 & 0.5 & 1 & 512 \\
\hline Spectinomycin & 1 & 4 & 8 & 32 & 4 & 8 & 16 & 32 \\
\hline Streptomycin & 1 & 2 & 16 & 512 & 1 & 2 & 8 & 256 \\
\hline Polymyxin E & 4 & 8 & 16 & 16 & 2 & 4 & 4 & 4 \\
\hline
\end{tabular}


Figure 1

A

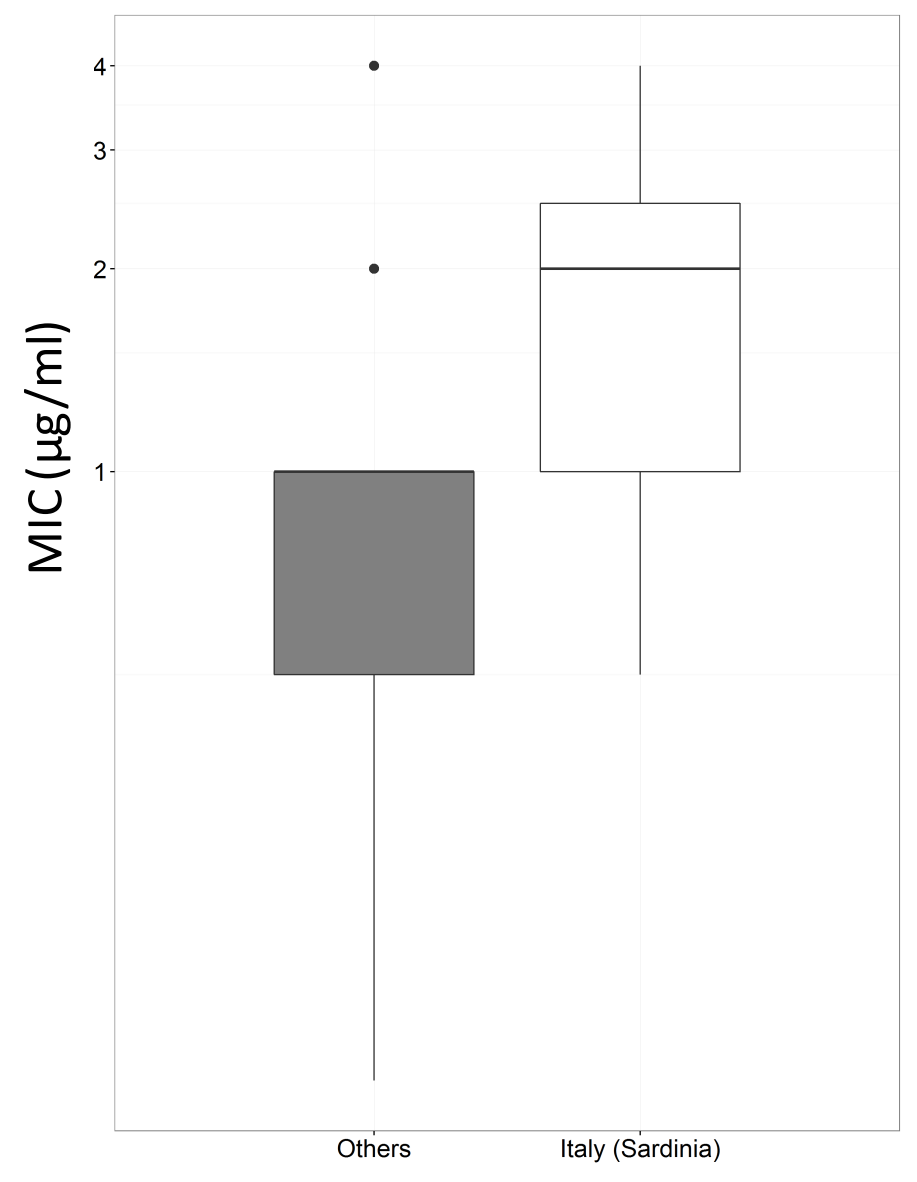

B

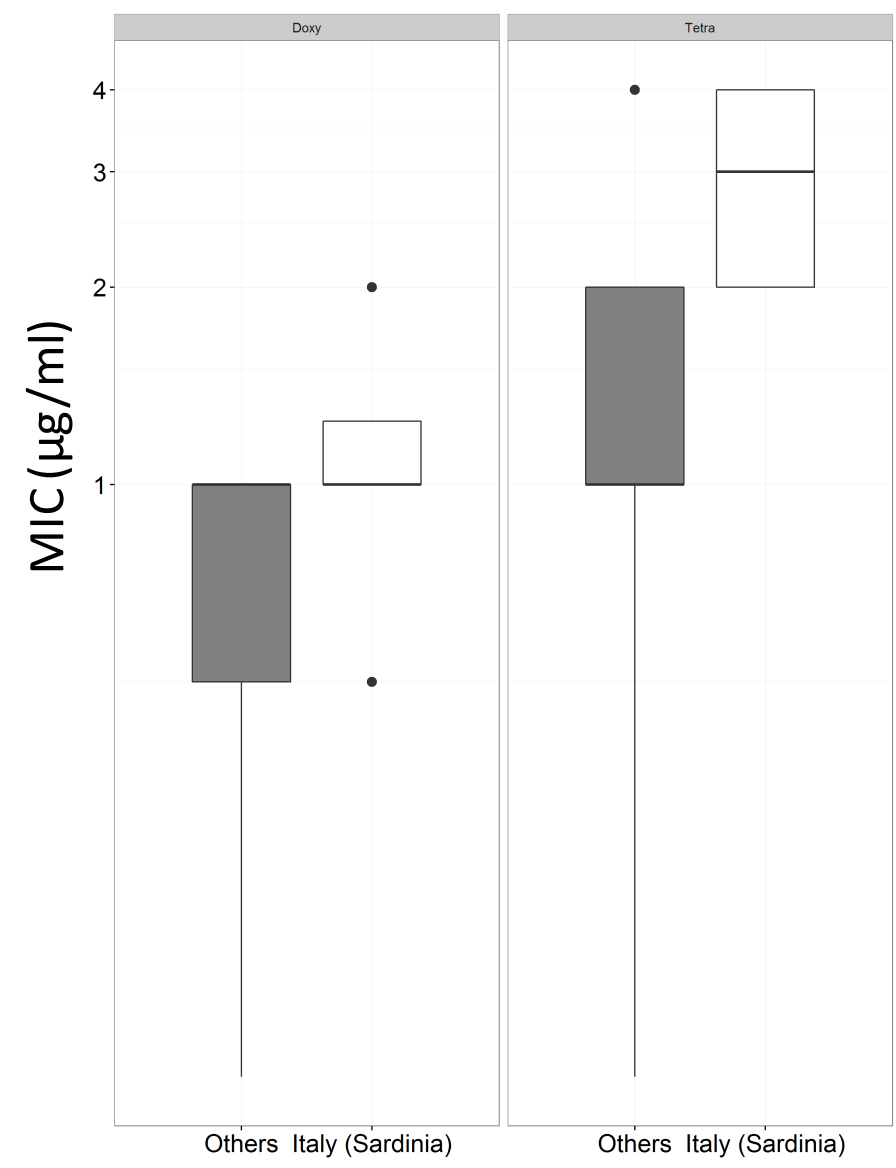

